\title{
Embitterment and Posttraumatic Embitterment Disorder (PTED): An Old, Frequent, and Still Underrecognized Problem
}

\author{
Michael Linden Christopher Patrick Arnold \\ Research Group Psychosomatic Rehabilitation, Department of Psychosomatic Medicine, Charité University \\ Medicine, Berlin, Germany
}

\section{History}

The founding father of modern psychiatric classification, Emil Kraepelin, dedicated a full chapter to "querulant delusion" in his textbook Psychiatry [1]. This disorder is a reaction to injustice which can be caused by legal disputes and conflicts with neighbors, family members, or public authorities. Individuals are obsessed with the wish to restore justice and/or to take revenge. They are ensnared by what has happened. They neglect all other areas of life. Embittered individuals can become so obsessed, that, in the end, according to Kraepelin, they may even be taken into custody. To emphasize the severe and disabling character of this disorder, Kraepelin calls it a "psychosis," specifically, a "reactive" psychosis, to clearly differentiate it from "endogenous" psychoses like schizophrenia. He stresses that it should also be differentiated from "querulant psychopathy" or personality disorders, which involves individuals behaving querulantly in certain situations but calming down when a dispute is resolved. A "querulant delusion" stems from a single traumatic event, becomes more and more exaggerated, and does not stop [2].

A similar problem has been described in Asia where "haan" is a feeling of remorse, victimization, unfairness, helplessness, and a deep urge to take revenge and to right the wrong, all as a consequence of unresolved injustice. This has been classified as a clinical entity, "Hwa-byung (fire disease)" [3]. Patients with Hwa-byung report strong feelings of frustration, pain, and somatization, with outbursts of anger and the wish to take revenge in response to social stressors like spousal infidelity, familial conflicts, or other forms of injustice and breaches of trust.

In Europe, this syndrome has been "rediscovered" and described as "posttraumatic embitterment disorder" (PTED), when such cases were seen more frequently as a result of the many stressors caused by the German reunification [4]. In summary, querulant delusion, Hwa-byung, and PTED describe virtually the same syndrome, interpreted as a reaction to social stressors and especially injustice.

Although "social stressors" like injustice, vilification, humiliation, and breach of trust are frequent, burdensome, and regularly associated with strong emotions and suffering, they have found less attention in psychiatric and psychosomatic discourse and research than the lifethreatening and anxiety-provoking stressors. There is no mention of the term or emotion "embitterment" in the ICD-10 (International Classification of Diseases, 10th revision) [5] or DSM-5 (Diagnostic and Statistical Manual of Mental Disorders, 5th edition) [6], let alone the term karger@karger.com

(C) 2020 S. Karger AG, Basel

www.karger.com/pps

Karger!
Michael Linden

FPR, Medizinische Klinik m.S. Psychosomatik

CBF, Hs IIIA, Hindenburgdamm 30

DE-12200 Berlin (Germany)

michael.linden@charite.de 
Table 1. Diagnostic criteria of posttraumatic embitterment disorder (PTED)

A. Core criteria

1. The patient responds with embitterment in direct relation to a negative life event which is experienced as injustice, humiliation, or breach of trust

2. The patient suffers from recurrent intrusional thoughts concerning the event and reacts with distinct emotional arousal when reminded of what has happened

B. Additional symptoms

1. The patient suffers from long-lasting dysphoric-aggressive-depressive mood reminiscent of depression with a somatic syndrome

2. The emotional modulation is unimpaired. The patient shows normal affect if he/she is distracted and is even able to smile at thoughts of revenge

3. Drive is reduced and seems to be blocked

4. The patient experiences him-/herself as a victim

5. The patient experiences a feeling of helplessness and finds themself unable to cope with the event and the consequences

6. The patient blames him-/herself for not having prevented the event or being unable to handle it

7. The patient does not care about what will happen to him/her and does not even know if he/she wants the wound to heal

8. The patient suffers from unspecific somatic symptoms, e.g., sleep disorder, loss of appetite, fatigue, tension

9. The patient shows phobic avoidance of people or locations related to the event

10. The patient has suicidal ideation

11. The patient has recurrent thoughts of revenge and/or fantasies of aggression or extended suicide

D. There is no mental disorder in the year before the critical life event, which can explain the symptoms

E. The disorder causes significant stress and impairment in daily life

F. The problem lasts longer than 6 months

"posttraumatic embitterment disorder." The editors of Psychotherapy and Psychosomatics are to be commended on having accepted publications on this subject over the last 2 decades, and now to invite us to write this editorial. We aim to provide an overview of the clinical and scientific developments in PTED, hoping to stimulate further research and a better recognition of it in clinical practice.

\section{Embitterment}

Embitterment is an emotion which is known to everybody [7]. Similar to anxiety, nobody needs a textbook to understand embitterment. It is a response to injustice, humiliation, and breach of trust. There is the nagging wish to undo what happened, reinstate justice, get even, and take revenge. The psychoanalyst Alexander [8] described embitterment as a masochistic defense reaction, as the affected individual continues to fight while accepting the self-destruction associated with embitterment. Embitterment can lead to dysfunctional behavior like social withdrawal, phobic avoidance, aggression, suicidality, and prolonged legal battles.

Embitterment manifests in many different ways [9], similar to anxiety. Almost everyone knows spells of embit- terment after experiencing insults or injustice. Normal embitterment recedes quickly, similar to a spell of anxiety when one is confronted by a growling dog. Then there is also stimulus-bound long-term embitterment. A person may generally behave inconspicuously and normally, but react with arousal and spells of embitterment whenever he or she is reminded of a special life event or person, such as a divorce, similar to experiencing persistent anxiety around dogs after one has been bitten. So far, this is all "normal".

Kraepelin [1] also described pathological embitterment, an intense and persistent reaction to a single event involving injustice, humiliation, and breach of trust. This can be paralleled to PTSD which is caused by a single lifethreatening and panic-provoking event. PTED ("querulant delusion") is a pathological reaction to an extraordinary but commonly occurring negative life event like a divorce, dismissal, personal insult, or vilification. Seemingly trivial events can lead to a severe and lasting embitterment reaction. It is irrelevant whether the injustice would be regarded by others as insignificant or severe. Corresponding to the transactional stress model, the crucial factor here is the individual's appraisal of, rather than the "objective" severity or nature of, the injustice [10].

PTED is classified as trauma, as the psychological status of the person switches from perfect health to chronic ill- 
ness and disability from one moment to the next. A chief characteristic of PTED (Table 1) is the prevailing and dominating embitterment in reaction to injustice, humiliation, and breach of trust. The duration, intensity, spreading, and resulting impairment are what distinguish normal from pathological embitterment, again similar to anxiety. Apart from embitterment itself, a variety of other pathological features can also be observed, i.e., dysphoric mood, intrusive thoughts, helplessness, self-blame, suicidal ideations, and emotional arousal when reminded of the past.

Severe embitterment is typically associated with ideations of revenge, aggression, and even homicide [11]. Not everybody who harbors aggressive ideation also has feelings of embitterment whereas embitterment regularly includes blaming somebody else and having ideas of revenge. The affected individuals do not give in, pursue their cause relentlessly, and show dysfunctional and querulant behavior. They are often cross-sectionally misdiagnosed as suffering from a personality disorder. However, the core problem is not querulant troublemaking but the intense emotion of embitterment which takes over the whole person in a similar way to anxiety. The term PTED therefore describes the problem better than "querulant delusion."

An unanswered question in need of further investigation is whether there is also a "complex PTED," which is not caused by a single but rather a sequence of humiliating events or the same situation persisting (i.e., analogous to complex PTSD).

It is also assumed, but not yet scientifically proven, that there are "embitterment-prone personalities," i.e., people who tend to feel insulted and react with embitterment even due to minor causes, similar to "anxious personalities." It could well be that some of the individuals who complain about recent embitterment-provoking experiences fall into this category [9].

There is an ongoing discussion on how to delineate embitterment from personality disorders [12-14]. This is undoubtedly also in need of further research. The clinical impression is that there is no special type of personality before the onset of the disorder. All personality types are at risk when individual core values and basic beliefs come under attack [15]. For some, this may have to do with their family, for others their career, for others money, etc.

A difficult diagnostic problem also arises when PTED occurs concurrently with other mental disorders. People with personality disorders are often the target of unjust and humiliating behavior. Schizophrenic patients experience their delusional persecution as unjust and a breach of their trust. These are risk factors for the development of comorbid PTED and require a thorough differential diagnosis.
Embitterment is an emotion that is distinct from other negative emotions and mental disorders. Depressed mood is a melancholic and anhedonic emotion, accompanied by reduced emotional modulation and a feeling of emotional numbness and nonreactivity. Embitterment, in contrast, is a full and explosive emotion [16]. Embitterment is different from panic and anxiety, which are characteristics of PTSD [17]. Anger or blame can occur with or without embitterment, depending on feelings of injustice or humiliation [18]. Hopelessness is seen in embittered people, but can also occur without an aggressive undertone. An interesting question is to what degree moral injury is related or different from embitterment reactions, as this is a disorder also caused by violation of one's basic beliefs [19].

\section{Measuring Embitterment}

The Bern Embitterment Inventory (BEI) [20] is an 18item self-rating instrument for the assessment of embitterment as a state or personality trait. It relates to general attitudes towards the world and general beliefs, e.g., "faults are criticized but commitment not honored" and covers the 4 dimensions "emotional embitterment," "activity-related embitterment," "pessimism/hopelessness," and "misanthropy/aggression."

Reactive and event-related embitterment can be assessed with the Post-Traumatic Embitterment Disorder Self-Rating Scale (PTED scale), available in different languages [21], the introductory statement refers to memories of a specific critical incident: "During the last years there was a severe and negative life event..." which is then followed by statements such as "...that hurt my feelings and caused considerable embitterment." Answers are given on a 5 -point Likert scale: $0=$ not true at all, $1=$ hardly true, 2 = partially true, $3=$ very true, and $4=$ extremely true. A mean total score of 1.6 is seen as a differentiation point for elevated embitterment, and 2.5 as an indicator of clinically relevant embitterment.

There is also a standardized diagnostic interview which asks for the core criteria of PTED [22]. The interviewer has to make a clinical decision as to whether the prevailing emotion is embitterment or some other negative feeling.

\section{Prevalence of Embitterment}

There are preliminary epidemiological data emerging from different continents and referring to different populations. In a Web-based survey in Korea of people aged 
18-35 years, $45.2 \%$ reported increased levels of embitterment which was related to greater exposure to negative life events [12]. In a nationwide online survey, You and $\mathrm{Ju}$ [23] found that $39.9 \%$ of respondents had an elevated PTED score $(1.60 \leq$ mean $<2.5)$ and $14.7 \%$ a clinically relevant score (mean $\geq 2.50$ ). These are only estimates of the true prevalence due to the online sampling procedure. In a quasi-epidemiological survey in a train, half of the respondents reported having experienced an embitterment-triggering negative life event during recent months. Elevated intensity of embitterment, which leads one to suspect PTED, was found in about $2.5 \%$ [24]. In psychosomatic patients, $26 \%$ showed increased embitterment [21]. These data confirm that embitterment is an emotion which is known to many individuals and that embitterment with pathological intensity is as frequent as many other mental disorders.

Persons who are exposed to negative life events are, as expected, at a higher risk of experiencing severe embitterment. This has been found in relation to grave changes in life, such as the German reunification, unemployment, the death of loved ones, severe somatic illnesses, problems at work, legal problems, and emigration [25-38].

\section{Causes of Embitterment}

Recent years have seen a surge of research and clinical awareness of stress-related disorders like PTSD [39] or prolonged grief [40,41]. Just as important, if not even more frequent and more important, are social and interactional stressors. It is the nature of humans to fight with each other, insult and downgrade others, and even take what belongs to others. This occurs frequently and can hurt and cause pain. Prominent interactional stressors are humiliation, vilification, breach of trust, and injustice. People feel humiliated when they have been downgraded, treated disrespectfully, blamed for no appropriate reason, or treated as inferior [42-47]. Vilification is disrespectful behavior, including harassment, incivility, bullying, emotional abuse, aggression, exclusion, and relational victimization [48-50]. Breach of trust and betrayal violate one's belief in the trustworthiness of another person and include when somebody takes inappropriate advantage of someone else if given the opportunity [51-55]. These social stressors severely affect the self-esteem of the victim. The presence of observers can amplify their dismay and anguish [46]. In a survey on psychosomatic patients, Bülau et al. [56] found in a sample of psychosomatic patients that the most fre- quent and burdensome negative life events were disappointing experiences and injustice, which explains the high prevalence of embitterment.

All of these interactional stressors are associated with injustice. It is unjust if someone else takes advantage of a situation, betrays another person, or bosses/harasses/ publicly belittles another person. Injustice is an especially severe social stressor. All humans hold the "belief in a just world," associated with the demand for justice, be it in general terms or individually [57-61]. This can be understood as an inborn basic belief or cognitive schema [15, 62] which can already be observed in little children, and is indispensable for interactions with other people, the organization of groups, and even societies. The belief in justice is the basis of social behavior and mediates a feeling of empowerment and "controllability of the world" $[59,63,64]$. Injustice is experienced as an act of aggression and downgrading, resulting in counteraggression. Victims of injustice strive to restore justice and their selfworth, if necessary, by taking revenge [50, 64, 65]. If this is accompanied with feelings like "there is no way out," degradation, and helplessness, embitterment is the natural response. This reaction can be described as a "last resort emotion" when the person feels cornered and does not see a way out of the situation. The individual will fight to get even but may also seek revenge without a positive goal and even accept their own self-destruction $[4,7,8]$. This feeling can become an obsessive quality, take over the whole personality, result in many additional symptoms, and impair functional behavior, so that a severe mental disorder results, similar to severe anxiety.

\section{The Treatment of Embitterment}

Most therapists know embittered patients. It is a challenge to treat such patients as they often reject the help of others. There are indicators which suggest that many embittered patients are treatment-resistant to general psychotherapeutic approaches. There are new and specific treatment concepts which refer to wisdom psychology [66]. Wisdom is a resilience factor, needed when one is confronted with stress in life, and has been referred to as "the ability to solve insolvable problems." It has been shown that wisdom is more important for life satisfaction than money or material things and contributes to resilience in the face of life burdens in general [67]. It can therefore be assumed that wisdom could also be a protective factor with regard to embitterment, although empirical proof is still pending. 
Wisdom therapy [68-70], based on cognitive behavioral therapy, tries to enhance the wisdom competencies of patients. These include an individual's view of the world, of other people, of oneself, and of the future, changing one's perspective, and acquiring/developing empathy, uncertainty tolerance, a long-term perspective, and forgiveness. As patients with PTED attribute the problem to outer events, but do not perceive the role of their emotional reaction, the treatment uses case vignettes of unsolvable problems with a victim, a perpetrator, and a third person who is benefitting. The goal is to overcome embitterment by reframing the negative life event and induce a new perspective and reorientation to the future.

\section{Embitterment and PTED in the ICD and DSM}

Although descriptions of this disorder appear already in the work by Kraepelin [1], there is only limited recognition of it in research and clinical practice. A reason for this might be that embitterment is a reactive and assumingly "understandable" phenomenon. It is therefore often overlooked that the problem is no longer the past event but rather the current crippling emotion. Another reason might be that the manifold symptoms of PTED can mimic alternative diagnoses, although PTED is a very distinct disorder. In contrast to PTSD, there is no life-threatening elicitor which causes horror in the case of PTED, and the leading emotion is not anxiety. If one looks at the published data on the "causes" of PTSD, the most frequent are rape, sexual assault, stalking, or the death of a loved one. This raises the question as to whether these really are cases of PTSD as consequence of a life-threatening experience, or rather PTED caused by humiliation or injustice [39]. PTED can help to clarify the PTSD concept and improve the diagnosis.

Depression is another frequently delivered diagnosis. However, with PTED, there is no anhedonic melancholic affect with reduced affect modulation. Embitterment is a full and dynamic emotion. Narcissistic or paranoid personality disorders are also considered. When recording a thorough history of a patient, in most cases there is no indicator for a personality disorder before the critical event. Burnout is sometimes diagnosed on account of the patient feeling overburdened; according to the ICD-11, this is a syndrome with feelings of energy depletion or exhaustion which refers specifically to the occupational context and it should not be applied to describe experiences in other areas of life. PTED patients are not exhausted, but rather dynamic, complaining, and aggres- sive. PTED can originate from problems at work, but also all other areas of life.

Finally, there is adjustment disorder. In the ICD-11, this is defined as an immediate maladaptive reaction to psychosocial stressors (e.g., divorce, illness or disability, socioeconomic problems, or conflicts at home or at work), characterized by a preoccupation with the stressor or its consequences (excessive worry, recurrent and distressing thoughts, a failure to adapt to the stressor, and significant impairment), but not justifying the diagnosis of another mental disorder, and typically resolving within 6 months, unless the stressor persists for longer. In the DSM-5, adjustment disorder is defined as response to an identifiable stressor with depressed mood, anxiety, or the disturbance of conduct, which causes marked distress and/or significant impairment, does not meet the criteria for another mental disorder, and does not persist for $>6$ months. These codes may be appropriate for embitterment reactions generally, which cause some distress and wane over time, similar to anxiety adjustment reactions.

PTED can be discriminated from adjustment disorder, just like PTSD, by looking at the cause, duration, severity, and type of syndrome. There is (1) a specific stressor (injustice); (2) a long duration with a tendency to increase, as already described by Kraepelin [1]; (3) a specific symptom profile, starting with the leading emotion of embitterment, accompanied by intrusions, dysphoric mood, multiple psychosomatic symptoms, blaming of others, ideations of revenge, and aggression; (4) severe maladaptive behavior and suffering, not only by the afflicted person, but those in their environment, who may be rejected, blamed, and attacked, even to the point of murder or suicide.

With regard to diagnostic codes and categories, $6 \mathrm{~B} 4 \mathrm{Y}$ (other specified disorders specifically associated with stress) of the ICD-11 [71] and 309.89 (other specified trauma- and stressor-related disorder) of the DSM-5 [6] may at present be the best fit for PTED, as they encompass a "disorder specifically associated with stress." These are, nevertheless, still inadequate, and a distinct code for PTED would be helpful for clinical practice and research. The lack of a specific category in the ICD and DSM is a major obstacle to proper diagnosis and treatment. In many clinical settings, mental health conditions are only diagnosed and treated if they fall within the DSM or ICD classifications. There have even been reviewers of international journals who have argued that empirical research into PTED cannot be published, as the disorder does not exist because it is not listed as a separate entity in these statistical manuals. It appears to thus be impor- 
tant that embitterment is mentioned explicitly in the diagnostic classifications, otherwise clinicians and researchers are likely to find they have to justify themselves when they address this problem.

When discussing whether PTED fulfils the requirements for a separate code in the ICD and DSM, one has to keep in mind that these are not clinical textbooks but "statistical manuals." According to the preface in ICD-11, they are the "foundation for the identification of health trends and statistics globally, and the international standard for reporting diseases and health conditions" for clinical and research purposes. Their limitations, especially those concerning psychosomatic practice and research, are well known and have been discussed extensively [72]. Science theory tells us that diagnostic terms do not reflect the "truth" or some "reality," but must be understood as hypothetical constructs which are qualified by operationalization, simplicity, and utility. Whether clinical syndromes are classified into separate categories does not depend on the proof of their validity in the sense of a "disease entity," but the utility of such a category [73-76].

The PTED concept fulfils all the core criteria of utility $[75,76]$. (a) It covers and organizes a broad spectrum of clinimetric data including symptoms, capacities and participation, and restrictions or impairment. (b) It includes elaborated concepts of etiology. (c) It is well operationalized and allows a separation from depression, PTSD, and other disorders. (d) Measures of embitterment correlate with each other and other related clinical measurements. (e) There is information on the course, chronicity, and prognosis of the disorder. (f) The concept and respective codes in the ICD and DSM also have direct implications for patient care. They help to identify such patients, properly diagnose the problem, and guide the treatment of a disorder which is otherwise difficult to treat. (g) In no way does the concept overpathologize everyday-life behavior, as these individuals are, in most cases, already in therapy, have several other diagnoses, and have been treated with different therapeutic measures [76]. It is not a question of first-hand labeling but of a differential diagnosis. (g) Such a code would possibly also allow for a better appraisal of other related problems and matching terms, e.g., moral injury, which must also be delineated from PTSD and adjustment disorders [19]. (h) As shown above, there is growing international research on this topic.

In summary, we are in agreement with Sensky [30] who claimed that the diagnosis of PTED brings with it a special clinical and scientific utility.

\section{Conflict of Interest Statement}

The authors have no conflicting interests to report.

\section{Funding Sources}

The authors have no funding sources to report.

\section{Author Contributions}

Both authors contributed to writing the manuscript.

\section{References}

1 Kraepelin E, editor. Psychiatrie: Ein Lehrbuch für Studierende und Ärzte. Klinische Psychiatrie III, ed 4. Leipzig: Johann Ambrosius Barth; 1915. pp. 1533-46.

2 Linden M. Querulant delusion and post-traumatic embitterment disorder. Int Rev Psychiatry. 2020;32:396-402.

3 Lin KM. Hwa-Byung: a Korean culturebound syndrome? Am J Psychiatry. 1983 Jan; 140(1):105-7.

4 Linden M. Posttraumatic embitterment disorder. Psychother Psychosom. 2003 Jul-Aug; 72(4):195-202

5 WHO. The ICD-10 Classification of Mental and Behavioral Disorders. Clinical Description and Diagnostic Guidelines. Geneva: World Health Organization; 1992.

6 American Psychiatric Association. The Diagnostic and Statistical Manual of Mental Disorders DSM-5 (5th ed). Arlington: American Psychiatric Publishing; 2013.
7 Linden M, Maercker A. Embitterment. Societal, psychological, and clinical perspectives. Vienna: Springer; 2011.

8 Alexander J. The psychology of bitterness. Int J Psychoanal. 1960;41:514-20.

9 Linden M, Rotter M. Spectrum of embitterment manifestations. Psychol Trauma. 2018 Jan;10(1):1-6.

10 Lazarus RS, Folkman S. Stress, Appraisal, and Coping. New York: Springer; 1984.

11 Linden M, Noack I. Suicidal and aggressive ideation associated with feelings of embitterment. Psychopathology. 2018;51(4):245-51.

12 Lee JH, Kim S. Exposure to Negative Life Events and Post-Traumatic Embitterment Symptoms in Young Adults in Korea: Cumulative and Differential Effects. Psychopathology. 2019;52(1):18-25.

13 Dodek A, Barnow S. Personality as risk and resilience in embitterment reactions. Embitterment. Vienna: Springer; 2011. pp. 83-100.
14 Blom D, Thomaes S, Bijlsma JW, Geenen R. Embitterment in patients with a rheumatic disease after a disability pension examination: occurrence and potential determinants. Clin Exp Rheumatol. 2014 May-Jun;32(3): 308-14.

15 Janoff-Bulman R, Morgan HJ. Victims' Responses of Traumatic Life Events: An Unjust World or an Uncaring World? Soc Justice Res. 1994 Jan;7(1):47-68.

16 Parker G, Roussos J, Eyers K, Wilhelm K, Mitchell P, Hadzi-Pavlovic D. How distinct is 'distinct quality' of mood? Psychol Med. 1997 Mar;27(2):445-53.

17 Kühn S, Düzel S, Drewelies J, Gerstorf D, Lindenberger U, Gallinat J. Psychological and neural correlates of embitterment in old age. Psychol Trauma. 2018 Jan;10(1):51-7.

18 Malle BF, Guglielmo S, Monroe AE. A theory of blame. Psychol Inq. 2014 May;25(2):14786. 
19 Griffin BJ, Purcell N, Burkman K, Litz BT, Bryan CJ, Schmitz M, et al. Moral injury: an integrative review. J Trauma Stress. 2019 Jun; 32(3):350-62.

20 Znoj H. Bern embitterment inventory. Bern: Verlag Hans Huber, Hogrefe AG; 2008.

21 Linden M, Baumann K, Lieberei B, Rotter M. The Post-Traumatic Embitterment Disorder Self-Rating Scale (PTED Scale). Clin Psychol Psychother. 2009 Mar-Apr;16(2):139-47.

22 Linden M, Baumann K, Rotter M, Schippan B. Diagnostic criteria and the standardized diagnostic interview for posttraumatic embitterment disorder (PTED). Int J Psychiatry Clin Pract. 2008;12(2):93-6.

23 You M, Ju Y. Modeling embitterment dynamics: the influence of negative life events and social support mediated by belief in a just world. J Affect Disord. 2020 Sep;274(274):269-75.

24 Linden M, Rotter M, Baumann K, Lieberei B, editors. Posttraumatic Embitterment Disorder. Definition, Evidence, Diagnosis, Treatment. Bern: Hogrefe \& Huber; 2007.

25 Linden M, Rotter M. Unemployment and embitterment in contrast to general psychological distress. Work. 2019;62(1):133-8.

26 Muschalla B, Linden M. Embitterment and the workplace. Linden M, Maercker A. editors. Embitterment Societal, psychological and clinical perspectives. Vienna: Springer; 2011; p. 154-67.

27 Muschalla B, Rau H, Willmund GD, Knaevelsrud $C$. Work disability in soldiers with posttraumatic stress disorder, posttraumatic embitterment disorder, and not-event-related common mental disorders. Psychol Trauma. 2018 Jan;10(1):30-5.

28 Michailidis E, Cropley M. Exploring predictors and consequences of embitterment in the workplace. Ergonomics. 2017 Sep;60(9): 1197-206

29 Chae JH, Huh HJ, Choi WJ. Embitterment and bereavement: the Sewol ferry accident example. Psychol Trauma. 2018 Jan;10(1):4650.

30 Sensky T. Chronic embitterment and organisational justice. Psychother Psychosom. 2010;79(2):65-72.

31 Blom D, Thomaes S, Kool MB, van Middendorp H, Lumley MA, Bijlsma JW, et al. A combination of illness invalidation from the work environment and helplessness is associated with embitterment in patients with FM. Rheumatology (Oxford). 2012 Feb;51(2): $347-53$.

32 Blom D, van Middendorp H, Geenen R. Anxious attachment may be a vulnerability factor for developing embitterment. Psychol Psychother. 2012 Dec;85(4):351-5.

33 Harth M, Nielson WR. Fibromyalgia and disability adjudication: no simple solutions to a complex problem. Pain Res Manag. 2014 Nov-Dec;19(6):293-9.

34 Ege H. Different typologies of workplace conflict and their connections with post traumatic embitterment disorder (PTED). Health. 2010 Jan;2(3):234-6
35 Siegel S, Milian M, Kleist B, Psaras T, Tsiogka $\mathrm{M}$, Führer D, et al. Coping strategies have a strong impact on quality of life, depression, and embitterment in patients with Cushing's disease. Pituitary. 2016 Dec;19(6):590-600.

36 Smith R. "Bitterness, shame, emptiness, waste": an introduction to unemployment and health. Br Med J (Clin Res Ed). 1985 Oct; 291(6501):1024-7.

37 Hahlweg K, Baucom DH. Relationships and embitterment. In: Linden M, Maercker A, editors. Embitterment. Societal, psychological, and clinical perspectives. Vienna: Springer; 2011. pp. 119-28.

38 Linden M, Teherani A. Embitterment and Not Psychological Distress Discriminates between Emigrants, Fugitives, and Residents. Psychother Psychosom. 2020;89(3):191-2.

39 Kessler RC, Aguilar-Gaxiola S, Alonso J, Benjet C, Bromet EJ, Cardoso G, et al. Trauma and PTSD in the WHO World Mental Health Surveys. European J Psychotraumatol. 2017 Jul;8(sup5):1353383.

40 Comtesse H, Vogel A, Kersting A, Rief W, Steil R, Rosner R. When does grief become pathological? Evaluation of the ICD-11 diagnostic proposal for prolonged grief in a treatment-seeking sample. Eur J Psychotraumatol. 2020 Jan;11(1):1694348

41 Scheibe S, Freund AM, Baltes PB. Toward a developmental psychology of Sehnsucht (life longings): the optimal (utopian) life. Dev Psychol. 2007 May;43(3):778-95.

42 Hartling I, Luchetta T. Humiliation: assessing the impact of derision, degraduation and debasement. J Prim Prev. 1999 Jun;19(4):259_ 78.

43 Lindner EG. Healing the cycles of humiliation: how to attend to the emotional aspects of "unsolvable" conflicts and the use of "humiliation entrepreneurship.". Peace Conflict. $2002 \mathrm{Apr} ; 8(2): 125-38$.

44 Coleman PT, Kugler K, Goldman JS. The Privilege of Humiliation: The Effects of Social Roles and Norms on Immediate and Prolonged Aggression in Conflict. Annual Conference of the International Association for Conflict Management (IACM); Budapest, Hungary; 2007.

45 Trumbull D. Humiliation: the trauma of disrespect. J Am Acad Psychoanal Dyn Psychiatry. 2008;36(4):643-60.

46 Walker J, Knauer V. Humiliation, self-esteem and violence. J Forensic Psychol. 2011 Oct; 22(5):724-41

47 Leidner B, Sheikh H, Ginges J. Affective dimensions of intergroup humiliation. PLoS One. 2012;7(9):e46375.

48 Crawshaw L. Workplace bullying? Mobbing? Harassment? Distraction by a thousand definitions. Consult Psychol J. 2009 Sep;61(3): 263-7.

49 Hoobler JM, Rospenda KM, Lemmon G, Rosa JA. A within-subject longitudinal study of the effects of positive job experiences and generalized workplace harassment on well-being. J Occup Health Psychol. 2010 Oct;15(4):434-51.
50 Wang Q, Bowling NA, Tian QT, Alarcon GM, Kwan HK. Workplace Harassment Intensity and Revenge: Mediation and Moderation Effects. J Bus Ethics. 2018 Jan;151(1): 213-34.

51 Child J, Rodrigues SB. Repairing the Breach of Trust in Corporate Governance. Corp Gov. 2004 Apr;12(2):143-52.

52 Walker K, Kutsyuruba B, Noonan B. The fragility of trust in the world of school principals. J Educ Adm. 2011 Aug;49(5):471-94.

53 Chen CC, Saparito P, Belkin L. Responding to trust breaches: the domain specificity of trust and the role of affect. J Trust Res. 2011 Jan; $1(1): 85-106$.

54 Grabois EW. The liability of psychotherapists for breach of confidentiality. J Law Health. 1998;12(1):39-84.

55 Sztompka P. Trust, Distrust and Two Paradoxes of Democracy. Eur J Soc Theory. 1998 Jan;1(1):19-32.

56 Bülau NI, Kessemeier F, Petermann F, Bassler M, Kobelt A. Evaluation von Kontextfaktoren in der psychosomatischen Rehabilitation. Rehabilitation. 2016;55(6):381-7.

57 Lerner MJ. The Belief in a Just World: A Fundamental Delusion. New York: Springer; 1980.

58 Hafer C, Sutton R. Belief in a Just World. In: Sabbagh C, Schmitt M, editors. Handbook of Social Justice Theory and Research. New York: Springer; 2016; pp. 145-60.

59 Donat M, Wolgast A, Dalbert C. Belief in a Just World as a Resource of Victimized Students. Soc Justice Res. 2018 Apr;31(2):13351.

60 Corey M, Troisi JD, Nicksa SC. Tipping the Scales of Justice: The Influence of Victimization on Belief in a Just World. Soc Justice Res. 2015 Sep;28(4):509-25.

61 Dalbert C. 2.3. Embitterment - from the perspective of justice psychology. In: Linden M, Maercker A, editors. Embitterment. Wien: Springer; 2011. pp. 30-41.

62 Samsonovich AV. Schema formalism for the common model of cognition. Biol Inspir Cogn Architect. 2018 Oct;26(4):1-19.

63 Dolinski D. The belief in an unjust world: A Egoistic Delusion. Soc Justice Res. 1996 Sep; 9(3):213-21.

64 Anderson CA, Bushman BJ. Human aggression. Annu Rev Psychol. 2002;53(1):27-51.

65 Kennedy DB, Homant RJ, Homant MR. Perception of injustice as a predictor of support for workplace aggression. J Bus Psychol. 2004 Mar;18(3):323-36.

66 Staudinger UM. A psychology of wisdom: history and recent developments. Res Hum Dev. 2008 Apr;5(2):107-20.

67 Linden M. Wisdom and wisdom psychotherapy in coping with stress. In: Koh KB, editor. Somatization and psychosomatic symptoms. New York: Springer; 2013. pp. 273-81.

68 Baumann K, Linden M. Weisheitskompetenzen und Weisheitstherapie - Die Bewältigung von Lebensbelastungen und Anpassungsstörungen. Lengerich: Pabst; 2008. 
69 Linden M, Baumann K, Lieberei B, Lorenz C, Rotter M. Treatment of posttraumatic embitterment disorder with cognitive behaviour therapy based on wisdom psychology and hedonia strategies. Psychother Psychosom. 2011;80(4):199-205.

70 Linden M, Lieberei B, Noack N. Wisdom Attitudes and Coping in Life of Psychosomatic Patients. Psychother Psychosom Med Psychol. 2019 Aug;69(8):332-8. German.
71 WHO. [Internet] International Statistical Classification of Diseases and Related Health Problems (ICD-11). World Health Assembly Update [cited 25 May 2019]. Available from: www.who.int/news-room/detail/2505-2019-world-health-assembly-update.

72 Porcelli P, Guidi J. The clinical utility of the diagnostic criteria for psychosomatic research: A review of studies. Psychother Psychosom. 2015;84(5):265-72.

73 Kendell R, Jablensky A. Distinguishing between the validity and utility of psychiatric diagnoses. Am J Psychiatry. 2003 Jan;160(1): 4-12.
74 Morey LC. Classification of mental disorder as a collection of hypothetical constructs. J Abnorm Psychol. 1991 Aug;100(3):289-93.

75 Fava GA, Rafanelli C, Tomba E. The clinical process in psychiatry: a clinimetric approach. J Clin Psychiatry. 2012 Feb;73(2):177-84.

76 Brand M, Rumpf HJ, Demetrovics Z, MÜller A, Stark R, King DL, et al. Which conditions should be considered as disorders in the International Classification of Diseases (ICD11) designation of "other specified disorders due to addictive behaviors"? J Behav Addict. 2020 Jun;1-10. 